\title{
Papers
}

\section{Evacuation decisions in a chemical air pollution incident: cross sectional survey}

\author{
S Kinra, G Lewendon, R Nelder, N Herriott, R Mohan, M Hort, S Harrison, V Murray
}

\begin{abstract}
Objective To compare the health outcomes in sheltered and evacuated populations after a chemical incident in a plastics factory.

Design Cross sectional survey.

Setting Urban area in southwest England.

Participants 1750 residents from the area exposed to the chemical smoke, of which 472 were evacuated and the remaining 1278 were advised to shelter indoors.

Main outcome measure Number of adverse health symptoms. A case was defined by the presence of four or more symptoms. Main results 1096 residents (63\%; 299 evacuated, 797 sheltered) provided data for analyses. The mean symptom score and proportion of cases were higher in evacuated people than in the sheltered population (evacuated: symptom score 1.9, cases $19.7 \%(\mathrm{n}=59)$; sheltered: symptom score 1.0 , cases $9.5 \%$ $(\mathrm{n}=76) ; \mathrm{P}<0.001$ for both). The difference between the two groups attenuated markedly at the end of two weeks from the start of the incident. The two main modifiable risk factors for the odds of becoming a case were evacuation (odds ratio 2.5, $95 \%$ confidence interval 1.7 to 3.8 ) and direct exposure to smoke for more than two hours on the first day of the incident $(2.0,1.7$ to 2.3). The distance of residence from the factory or level of exposure before intervention (first six hours) had little effect on the odds of a person becoming a case.

Conclusions Sheltering may have been a better protective action than evacuation in this chemical incident, which is consistent with the prevailing expert view. Although this study has limitations, it is based on a real event. Evacuations carry their own risks and resource implications; increased awareness may help to reduce unnecessary evacuations in the future.
\end{abstract}

\section{Introduction}

The accidental release of toxic chemicals into the community may pose acute and long term health hazards (possibly including cancers, congenital malformations, and psychosomatic illnesses) and lead to tremendous public anxiety. ${ }^{1-3}$ In the event of such a chemical incident, where the public may be exposed to a cloud of toxic vapour, two options of protective action exist-sheltering or evacuation. The prevailing expert view for public health protection in chemical air pollution incidents is to shelter rather than evacuate the exposed population. ${ }^{4-7}$ However, this is based largely on experimental and modelling data, and we found no comparative data from actual incidents.

A fire started in a factory manufacturing plastic goods in southwest England. The factory was situated on an industrial estate adjoining a large urban residential area. The initial response of the emergency services was to start evacuating residents from their homes to a nearby leisure centre. This decision was subsequently reviewed by the members of the emergency response team, and further evacuation was stopped, with residents advised to shelter and stay inside their homes. The resultant partial evacuation offered an opportunity to compare the relative health protection offered by these two modes of intervention. We therefore carried out a cross sectional postal questionnaire survey on residents in the affected area and compared the health outcomes among the people evacuated (one third) and sheltered (two thirds).

\section{Methods}

We produced a health questionnaire that was administered to all people living in the area that was exposed to the chemical smoke (evacuated 472, sheltered 1278).

\section{Questionnaire}

We modified the questionnaire from model questionnaires produced by the Chemical Incident Response Service (Guy's and St Thomas' Hospital, London) and National Focus for Chemical Incidents (Department of Health, Cardiff). The questions related to demographic factors; places of residence over the 48 hour period after the incident; time spent outdoors; and likely symptoms of ill health and existing health status, such as medical conditions and smoking habits. We asked respondents to report health symptoms if they had occurred at all and if they persisted at the time of completion of the questionnaire (persistent symptoms). The questionnaire went out at the end of the first week of the incident, and a reminder was delivered at six weeks through an article in the local newspaper. A repeat questionnaire with a reminder went to people who had not replied at two months.

\section{Defining exposure and outcome}

We identified the exposed population on the map by drawing a semicircular arc from the incident site in the direction of the greatest density of smoke, which we established by chemical meteorological data. Where the arc intercepted small streets, we either included or excluded the whole street, whichever the greater proportion. The maximum distance from the factory that was permissible for inclusion in the study was 1000 metres.

Since we did not have any direct measures of individual exposure we used two proxy measures: distance of the place of residence from the factory and an objective measure of relative exposure at each of the places where the respondents stayed. We used easting (distance east) and northing (distance north) grid references for each postcode including the factory, to calculate the distances in straight lines (in metres) by using a formula based on the Pythagoras theorem. For the objective exposure, 
the Met Office undertook atmospheric dispersion modelling, using the Numerical Atmospheric dispersion Modelling Environment (NAME III). ${ }^{8}$ We used real time meteorological data from the nearby meteorological station to run the model to predict relative concentrations of pollutants over the 48 hour duration of the incident. We swapped the relative concentrations of pollutants at each of the postcodes on the geographical information system ArcView, version 3.0 (ESRI, Redlands, California, USA) for two time frames (the initial six hours and 48 hours); six hours being the median time to evacuation.

For our analyses, we considered the exposure score for the initial six hours as the primary exposure, since it represents the actual exposure before the intervention, on which the decision was based. We also calculated a cumulative exposure score over 48 hours by adding exposures over time spent by the participant at each of the postcodes. Of the people who were evacuated, roughly two thirds went to the designated evacuation site (leisure centre), and the remaining third went to other convenient places, such as homes of friends and family. We asked people who were evacuated to provide the address and postcode of the place where they stayed, if different from the leisure centre, and substituted these postcodes accordingly. If the evacuation postcode was also in the exposed area then we used the exposure score for that postcode; otherwise they were given a null value. The cumulative, 48 hour exposure score is difficult to interpret as it constitutes an inherent element of intervention, in addition to the participants being generally indoors (and so not necessarily exposed to that level of pollutants in the environment).

Acute symptoms produced by chemical smoke exposure are generally similar to those caused by common viral respiratory illnesses. Because of this lack of specificity of symptoms, we decided to define cases on the basis of number of symptoms. We established baseline prevalence of symptoms for the period (winter) by simultaneously administering the questionnaire to a random $10 \%$ sample $(n=1000)$ of residents from a neighbouring town with a similar demographic and socioeconomic profile. We calculated the mean symptom score (total number of symptoms per person) for the residents of the unexposed town and regarded all those with a symptom score greater than 2 standard deviations of the mean as cases. We defined persistent cases similarly, but with symptoms persisting at the time of completing the questionnaire (which was at least two weeks from the time of the incident). The symptoms considered were runny eyes, swollen eyelids, sore throat or nose, shortness of breath, cough, skin rash, skin burns, nausea, vomiting, abdominal pain, diarrhoea, fever, wheezing or asthma, palpitations, headache, lightheadedness, and blurred vision. We gave each symptom an equal weighting of one (present) or zero (absent).

\section{Data from environmental sampling and healthcare services} Environmental samples, based on the expected emissions, were taken repeatedly over a 48 hour period. Among the gaseous emissions, samples we tested for included hydrogen chloride, hydrogen cyanide, hydrogen fluoride, isocyanides, and styrene. We used chemical tubes (Draeger, Aqua Air Industries, Louisiana, US) to carry out these tests. The first air testing started some 12 hours after onset of the fire, inside and immediately outside the burning factory, in dense acrid smoke, and 100 metres downwind within the smoke plume. Other environmental investigations included tests for acidity of surface water; asbestos fibre counts in air and on hard surfaces; and levels of dioxins and furans in soil, grass, debris, and water samples. We collected information about health effects from people seeking medical help as a result of exposure. We collected information

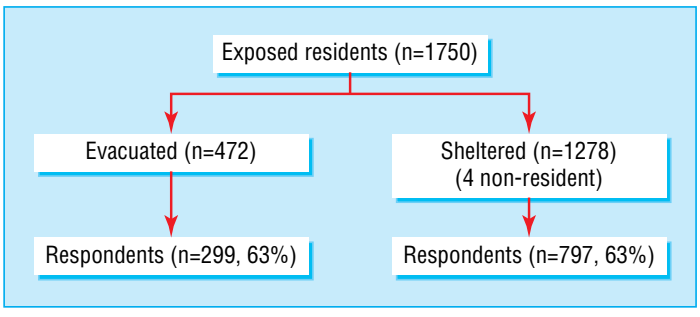

Fig 1 Flow of participants through the study

from all relevant sources of medical advice including ambulance and emergency departments as well as the local general practitioners and telephone helplines.

\section{Statistical analysis}

We used multiple logistic regression to estimate the likelihood of a person becoming a case for each of the independent risk factors. We used Stata, version 8 (StataCorp, College Station, Texas, USA), for our analyses.

\section{Results}

We received $1096(63 \%)$ completed questionnaires from the exposed residents; four respondents sent back unfilled questionnaires to say that they were away at the time, and we excluded these from further analyses. The respondents were older and the proportion of female respondents was higher than among the non-respondents (respondents: median age 49 years, 53\% female; non-respondents: median age 33 years, $46 \%$ female).

Of the people who received questionnaires in the adjacent unexposed town, 334 (33\%) replied. The mean symptom score

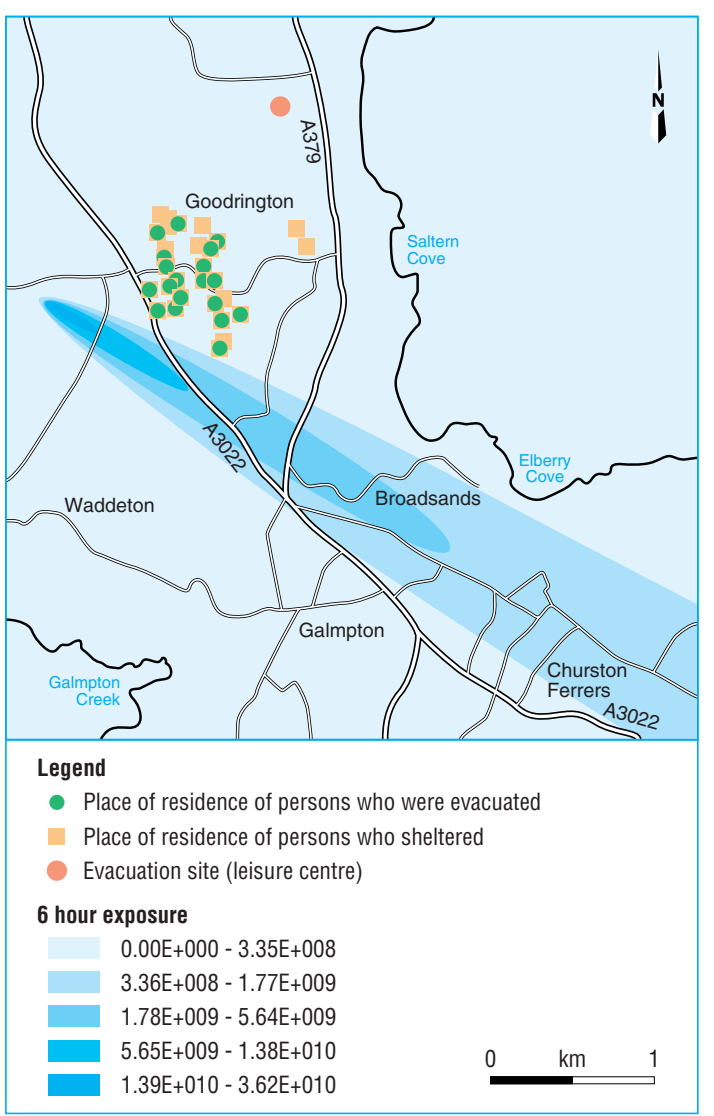

Fig 2 Location of residences by initial six hour exposure 
Table 1 Characteristics of residents exposed to the chemical smoke. Values are numbers (proportions) of subjects unless otherwise indicated

\begin{tabular}{lccc} 
Characteristic & $\begin{array}{c}\text { Evacuated } \\
(\mathbf{n}=\mathbf{2 9 9})\end{array}$ & $\begin{array}{c}\text { Sheltered } \\
(\mathbf{n}=797)\end{array}$ & P value \\
\hline Mean (SD) age in years & $46.3(24.3)$ & $45.3(24.3)$ & 0.55 \\
\hline Female sex & $162(54)$ & $423(53)$ & 0.73 \\
\hline Mean (SD) No of symptoms & $1.9(2.3)$ & $1.0(1.8)$ & $<0.001$ \\
\hline Mean (SD) No of persistent symptoms & $0.4(1.2)$ & $0.2(0.9)$ & 0.002 \\
\hline Cases (four or more symptoms) & $59(19.7)$ & $76(9.5)$ & $<0.001$ \\
\hline $\begin{array}{l}\text { Persistent cases (four or more } \\
\text { symptoms after two weeks of } \\
\text { incident) (\%) }\end{array}$ & $10(3.3)$ & $15(1.9)$ & 0.15 \\
\hline $\begin{array}{l}\text { Median (range) distance of residence } \\
\text { from the factory in metres }\end{array}$ & $565(217-791)$ & $572(217-791)$ & 0.51 \\
\hline $\begin{array}{l}\text { Mean exposure score before the } \\
\text { intervention (initial six hours) in } \\
\text { g/m }{ }^{3} \text { (SD) }\end{array}$ & $0.01(0.03)$ & $0.04(0.11)$ & $<0.001$ \\
\hline $\begin{array}{l}\text { Spent more than 2 hours outdoors on } \\
\text { first day (\%) }\end{array}$ & $59(19.7)$ & $127(15.5)$ & 0.096 \\
\hline $\begin{array}{l}\text { Spent more than 2 hours in direct } \\
\text { smoke on first day (\%) }\end{array}$ & $12(4)$ & $21(2.6)$ & 0.33 \\
\hline \begin{tabular}{l} 
Potential risk factors: \\
\hline Asthma
\end{tabular} & $29(9.7)$ & $61(7.7)$ & 0.27 \\
\hline Bronchitis & $7(2.3)$ & $11(1.4)$ & 0.27 \\
\hline Heart disease & $17(5.7)$ & $29(3.4)$ & 0.08 \\
\hline Eczema & $5(1.7)$ & $20(2.5)$ & 0.44 \\
\hline Hay fever & $46(15.4)$ & $105(13.2)$ & 0.34 \\
\hline Cigarette smoking & & \\
\hline
\end{tabular}

was 0.48 (SD 1.41). On the basis of this, we regarded all those with four or more symptoms as cases for the purposes of this study (case definition: greater than 2 standard deviations of the mean in unexposed area).

In the exposed area, the response rate (63\%; respondents: 299 evacuated and 797 sheltered) and median response time (42 days; range: 1-66 days evacuated and 2-65 days sheltered) among the evacuated and sheltered populations were identical (fig 1). Figure 2 shows the location of the postcodes of residence of the sheltered and evacuated respondents in relation to the density and direction of smoke plume during the initial six hours. The figure and the calculated median distance from the factory (evacuated homes: 565 metres; sheltered homes: 572 metres; range for both: 217-791 metres) show that the evacuated and sheltered residents were similarly exposed to the smoke plume. Table 1 shows the characteristics of the evacuated and sheltered respondents. Multivariate analysis showed that evacuation and direct exposure to smoke on the first day of the incident were the two main modifiable risk factors for the odds of becoming a case, while the actual distance of residence from the factory or the exposure before the intervention (initial six hours) seemed to be of little importance (table 2).

Table 2 Best model $\left(R^{2}=0.15\right)$ for odds of becoming a case

\begin{tabular}{|c|c|c|}
\hline \multirow[b]{2}{*}{ Risk factor } & \multicolumn{2}{|c|}{ Odds ratios $(95 \% \mathrm{Cl})$} \\
\hline & Unadjusted & Adjusted $^{\star}$ \\
\hline Age in years & 0.98 (0.98 to 0.99$)$ & 0.98 (0.97 to 0.99 ) \\
\hline $\begin{array}{l}\text { Distance of residence from factory } \\
\text { (100 metres) }\end{array}$ & 1.00 (0.99 to 1.00$)$ & 1.00 (0.99 to 1.00$)$ \\
\hline $\begin{array}{l}\text { Exposure score before intervention } \\
\text { (initial six hours) in } \mathrm{g} / \mathrm{m}^{3}\end{array}$ & 0.68 (0.09 to 5.08$)$ & 2.03 (0.19 to 22.07) \\
\hline Evacuated & 2.33 (1.61 to 3.38 ) & 2.54 (1.68 to 3.82 ) \\
\hline $\begin{array}{l}\text { Spent more than } 2 \text { hours in direct } \\
\text { smoke on first day }\end{array}$ & 1.93 (1.65 to 2.26$)$ & 1.98 (1.67 to 2.34 ) \\
\hline Asthma & 3.34 (2.03 to 5.50$)$ & 3.21 (1.86 to 5.54 ) \\
\hline Cigarette smoker & 1.42 (0.88 to 2.29$)$ & 1.17 (0.69 to 1.99$)$ \\
\hline
\end{tabular}

${ }^{*}$ Adjusted for other risk factors.
Of the people who had been evacuated, 195 went to the designated site (leisure centre) and $104(35 \%)$ to other places, such as homes of friends and family. Of those who evacuated to other sites, 73 people provided accurate addresses, and for these we used appropriate exposure scores (zero for 23 people who went out of area); for the remaining 31 people we could not calculate the 48 hour exposure. The mean 48 hour exposure score (based on slightly fewer subjects, $\mathrm{n}=1065$ ) was similarly higher for the sheltered residents (evacuated 0.01 (SD 0.03) $\mathrm{g} / \mathrm{m}^{3} v$ sheltered $\left.0.04(0.11) \mathrm{g} / \mathrm{m}^{3} ; \mathrm{P}<0.001\right)$, and contributed little to the odds of a person becoming a case (crude odds ratio 0.99, 95\% confidence interval 0.99 to 1.00); unchanged after adjustment for all other variables in table 2; fig 3).

\section{Environmental sampling}

The first air testing carried out 12 hours after the start of the incident, inside and immediately outside the burning factory, in dense acrid smoke showed the maximum concentration of 5 parts per million of hydrochloric acid. Concentrations of other gases tested were less than 1 part per million. Tests 100 metres downwind within the smoke plume detected 1 part per million of hydrochloric acid and other gases below detection levels. Further tests carried out at various distances and timings over the next two days found readings below detection levels. Tests for the $\mathrm{pH}$ carried out on puddle water in the area showed neutral readings. Counts for airborne asbestos fibres and other bulk and swab samples did not show any evidence of asbestos. Samples tested for dioxins and furans showed concentrations at or below those expected under normal circumstances.

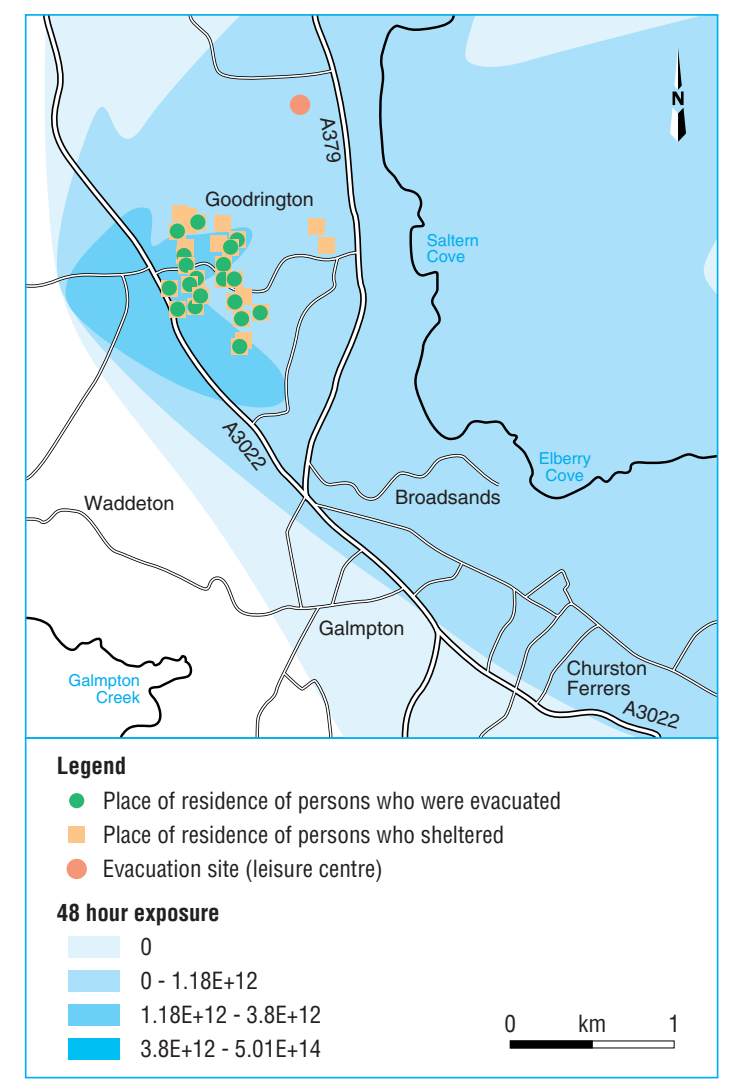

Fig 3 Location of residences by 48 hour exposure 


\section{Health effects identified from people seeking medical help as a result of the exposure}

Information available from medical inquiries included emergency services personnel $(n=31)$ and local residents $(n=23)$. The symptoms described were consistent with the mild symptoms described above, such as sore throat, cough, runny eyes, and skin irritation. Two people were admitted to hospital, one for acute attack of bronchial asthma and the other for suspected angina. Both had been evacuated and were admitted at the time of evacuation.

\section{Discussion}

In two groups of residents similarly exposed to smoke plume from a chemical incident, evacuation did not confer any additional health benefit over sheltering. If anything, evacuated residents seemed to have more ill health effects soon after the incident than sheltered residents, although the difference did not seem to persist beyond two weeks. Although our study has limitations, it is a comparative study that is based on a real incident. The results reinforce the prevailing expert view that favours sheltering over evacuation as a response to protect populations exposed to chemical air pollution incidents. Evacuations carry their own risks and resource implications; increased awareness may help to reduce unnecessary evacuations in the future.

\section{Limitations of the study}

The study has some limitations. An important concern is that the level and nature of smoke exposure could have been different between the evacuated and sheltered groups of residents. We have tried to estimate the exposure in two different ways: distance of the residence from the factory and atmospheric dispersion modelling of the pollutants by using the NAME III model. This model was originally designed for dispersion modelling of radioactive material, but it can also be used to model dispersion of chemicals in the atmosphere. ${ }^{8}$ Dispersion modelling of this type has some uncertainties-for example, we had no information about thermal buoyancy of the plume or the exact nature of the pollutants released. The NAME model, however, is widely used for dispersion modelling, and, given the closeness of the meteorological station, the results would be expected to be of reasonable accuracy. ${ }^{8}$ This type of work represents an improvement on standard methods of assessing exposure, such as simply using distance as a proxy for exposure..$^{9-11}$

Self reported symptoms in the people who had been evacuated could be the result of a combination of physical effects of the smoke and the psychological impact of evacuation. ${ }^{12}{ }^{13}$ We did not include any instruments to assess the psychological impact of the incident and so were unable to separate the two. However, self reported symptoms could be considered appropriate in this context where the perception of ill health is as relevant as physical ill health itself, especially with regards to long term psychological impact and anxiety. This study has looked at early health outcomes only, which may differ from long term health outcomes. Clustering of the responses and health effects among members of the same household is a limitation of this study, but we did not have the required data to incorporate in the analyses. Results, in one previous study that accounted for clustering, remained largely unaltered. ${ }^{10}$

\section{Comparison with other studies}

No other comparative studies are available to which we could relate our findings. Previous studies looking at the health effects of chemical incidents have entailed either sheltering or

\section{What is already known on this topic}

Populations exposed to chemical air pollution incidents are often evacuated by the emergency services as a means to safeguarding their health

Expert guidance favours sheltering indoors over evacuation as the emergency response; however, this advice is based on experimental and modelling data, and no comparative data from actual incidents exist

The lack of a good evidence base may be undermining adherence to expert guidance

\section{What this study adds}

Sheltering may have been a better protective action than evacuation in this chemical incident, which is consistent with the prevailing expert view

Evacuations carry their own risks and resource implications

Increased awareness may help to reduce unnecessary evacuations in the future

evacuation. ${ }^{10}{ }^{11}{ }^{14-16}$ In one previous study of a fire in a plastics factory, the residents were advised to shelter and did not report any serious side effects. ${ }^{14}$ The theoretical basis for expert advice favouring sheltering over evacuation is that protection offered by barriers between the exposure and the population is at least as effective as the protection offered by increasing the distance between the exposure and the population-that is, evacuation. Evacuations generally entail taking the population out of the barrier zone and moving them through a much higher exposure, albeit for a shorter duration. Our results show that direct exposure to smoke is a more important determinant of ill health than the cumulative exposure to smoke and these results are consistent with those reported from other studies. ${ }^{611}$

\section{Reasons for evacuation}

Despite the expert guidance, an unacceptably high proportion of chemical incidents worldwide result in evacuations. Possible reasons for these include an instinctive response on the behalf of emergency services to evacuate populations in danger, and the preference to "play it safe" by first responders. ${ }^{6}$ Initial decisions are often taken under very stressful conditions that do not allow time for reflection. Lack of experience has also been proposed as a possible reason since greater frequency of evacuations is reported from areas where chemical incidents are uncommon. ${ }^{17}$ Another common factor is the delay in getting appropriate public and environmental health advice.

\section{Conclusion}

Sheltering may have been a better protective action than evacuation in this chemical incident. Although our study has several limitations, it is based on a real event. These results are consistent with the expert view that favours sheltering as the mode of action in serious chemical air pollution incidents. Evacuations carry their own risks and resource implications. Increased awareness among emergency services may help to reduce unnecessary evacuations in the future.

We thank the participants in this study for taking the time to complete the questionnaires. We also appreciate the help provided by Geoff Chamings and Shaun Carter at Devon County Council, who converted the postcode references into distance between the factory and the residences. 
Contributors: SK, GL, RN, SH, and VM were involved in the conduct of the study. NH, RM, and MH produced the exposure data and maps. SK analysed the data and wrote the first draft of the paper. All authors contributed to the final manuscript. SK is the guarantor.

Competing interests: None declared.

Funding: None.

Ethical approval: Not required at the time. The study was carried out in 1999, when ethics approval was not considered an issue for such studies conducted by health agencies as part of their responsibility.

1 Reggiani G. Medical problems raised by the TCDD contamination in Seveso, Italy. Arch Toxicol 1978;40:161-88.

2 Gray J. Characteristic patterns of and variations in community response to acute chemical emergencies.J Hazardous Materials 1981:4:357-65.

3 Bofetta P. Carcinogenicity of trace elements with reference to evaluations made by the International Agency for Research on Cancer. Scand J Work Environ Health 1993;19:6770 .

4 Purdy G, Davies PC. Toxic gas incidents-some important considerations for emergency planning. In: The assessment and control of major hazards. Rugby: Institute of Chemical Engineers, 1985.

5 NHS Executive. Deliberate release of biological and chemical agents: Guidance to help plan the health service response. London: Department of Health, 2000.

6 Essery G. On site emergency planning and the use of predictive techniques.J Loss Prevention in the Process Industries 1991;4:44-8.

7 Essery G. Chemical incident: evacuate or shelter. Safety Health Practitioner 1994;12:22-5.

8 Jones A, Thomson D, Hort M, Devenish BJ. The UK Met Office's next-generation atmospheric dispersion model, NAME III. Proceedings of the NATO CCMS international technical meeting on air pollution modelling and its application (October 2004). Banff, Canada: Kluwer (in press).

9 Williams FLR, Ogston SA. Identifying populations at risk from environmental contamination from point sources. Occup Environ Med 2001;59:2-8.

10 Morris, RD. Human health effects of a spill of aromatic distillates in Superior, Wisconsin Atlanta: Agency for Toxic Substances and Disease Registry, Division of Health Studies, 1997.

11 Bauer U, Berg D, Kohn MA, Meriwether RA, Nickle RA. Acute effects of nitrogen dioxide after accidental release. Public Health Rep 1998;113:62-70.
12 Fiedler N, Udasin I, Gochfled M, Buckler G, Kelly-McNeil K, Kippen H. Neuropsychological and stress evaluation of a residential mercury exposure. Environ Health Perspec 999;107:343-7.

13 Dayal HH, Baranowski T, Li YH, Morris R. Hazardous chemicals: psychosocial dimensions of the health sequelae of a community exposure in Texas.J Epidemiol Community Health 1994;48:560-8.

14 Baxter PJ, Heap BJ, Rowland MG, Murray V. Thetford plastics fire, October 1991: the role of a preventative medical team in chemical incidents. Occup Environ Med $1995 ; 52: 694-8$.

15 Kizer KW, Garb LG, Hine CH. Health effects of silicon tetrachloride. J Occup Med 1984;26:33-6.

16 National Transportation Safety Board. Railroad accident report-Derailment of Illinois central gulf railroad freight train extra 9629 East (GS-2-28) and release of hazardous materials at Livingstone, Louisiana, September 28, 1982. Washington, DC: Bureau of Technology, 983.

17 Sorenson JH. Evacuations due to off-site releases from chemical accidents: experience from 1980 to 1984. J Hazardous Materials 1987;14:247-57. (Accepted 19 April 2005)

BMJ 2005;330:1471

Department of Social Medicine, University of Bristol, Bristol BS8 2PR $\mathrm{S}$ Kinra lecturer in epidemiology and public health medicine

Public Health Development Unit, Plymouth Teaching Primary Care Trust, Plymouth PL1 2AD

G Lewendon consultant in public health medicine

$\mathrm{R}$ Nelder public health information specialist

Chemical Hazards Unit, Health Protection Agency, Guy's and St Thomas' Hospital Trust, London SE14 5ER

N Herriott environmental epidemiologist

$\mathrm{R}$ Mohan research engineer

V Murray professor

Met Office, Exeter EX1 3PB

M Hort research scientist

Southwest Peninsula Health Protection Unit, Devon Team, Dartington TQ9 6JE

S Harrison consultant in communicable disease control

Correspondence to: S Kinra Sanjay.Kinra@bristol.ac.uk

\title{
Commentary: Evacuation decisions in chemical incidents benefit from expert health advice
}

\author{
Peter J Baxter
}

Kinra et al have evaluated symptoms arising from a fire at a plastics factory that lasted 48 hours, in which partial evacuation of the area took place in the first six hours, with most residents remaining indoors for the rest of the emergency. ${ }^{1}$ Statutory emergency planning and advice for people living around designated hazardous installations that manufacture or store chemicals has been based on mathematical modelling of the most likely scenarios for the catastrophic failure of storage vessels or other failures in the plant, in which the duration of flow of a cloud of chemicals that are accidentally released, neutral, or denser than air will be less than 30 minutes (the average time for countermeasures to be implemented). ${ }^{2}$ Peak exposure to an individual living or working nearby at the time when such a chemical cloud disperses should be higher outdoors than inside a building with its doors and windows closed, at least for this short period of time. The difference will depend on how well the building has been sealed against the weather, to reduce normal air infiltration rates. Once the danger has passed, the emergency services would tell people to go outside into the fresh air. Attempts at rapid escape or evacuation are considered to be more dangerous than taking shelter indoors in such short term emergencies, but the adverse health consequences that may follow from this strategy - particularly the effects of exposure to low, cumulative levels of irritant gases in people with asthma and chronic lung disease who do take shelter-need to be studied whenever these unusual incidents occur.
This "stay indoors" strategy may not necessarily apply to certain chemical incidents of longer duration. Smoke from plastics fires usually contains a mixture of highly irritant substances, together with combustion gases, which for polyvinyl chloride (PVC) is mostly hydrogen chloride ( $\mathrm{HCl})$. Kinra et al measured 1 part per million of hydrogen chloride in the ambient air of the residential area on their first testing at 12 hours, and thereafter hydrogen chloride and other gases were undetectable. This very soluble gas is unlikely to produce any reactions in people with asthma at this concentration, and healthy individuals can be exposed to higher levels for prolonged periods without ill effects. ${ }^{3}$ Other irritants in the smoke will have an additive effect. Acute incidents involving the inhalation of irritant gases (which are among the most important materials stored at major hazard installations and commonly emitted in fires) may, in severe cases, cause toxic pneumonitis and even death, and brief exposure may trigger reactive airways dysfunction syndrome (RADS; irritant induced asthma). ${ }^{3}$ Kinra et al showed that the adverse respiratory consequences in people with asthma and others were few and concluded that remaining indoors was a safe option in the fire they reported. ${ }^{1}$

Temporary evacuation may nevertheless be advisable where a toxic release is threatened, such as in a crash involving a road or rail tanker containing toxic gas. Plumes from burning chemical warehouses, tyre dumps, or plastic stores are usually buoyant from the heat of the fire and may present little immediate risk, 
but whether they descend to ground level long enough to cause a hazard to the people indoors, and the range at which people could be affected, will depend on the management of the fire by the fire services, the type of materials involved, the wind and weather forecasts, and local topography. ${ }^{4}$ In warehouse fires, chemical fallout from the plume may contaminate nearby gardens and buildings. ${ }^{5}$ As these chemical fires can last for hours, or even days, temporary evacuation when conditions permit should always be considered, ideally with advice provided to the emergency services by a public health response team. ${ }^{4}$ More epidemiological studies with good information on exposure will be essential to build the evidence base for decision making in chemical releases and for management after the incident.

1 Kinra S, Lewendon G, Nelder R, Herriott N, Mohan R, Hort M, Harrison S, Murray V. Evacuation decisions in chemical air pollution incidents: cross sectional survey. $B M J$ 2005;330:1471-4.
2 Health and Safety Executive. Control of major accident hazards (COMAH). www.hse.gov.uk/comah/index.htm (accessed 31 May 2005).

3 Department for Environment, Food and Rural Affairs. Expert Panel on Air Quality Standards. Guidelines for halogens and hydrogen halides in ambient air for protecting human health against acute irritancy effects. Consultation document. London: Defra, 2005. www.defra.gov.uk/environment/airquality/ags/index.htm

4 Baxter PJ, Heap BJ, Rowland MGM, Murray VSG. Thetford plastics fire, October 1991: the role of a preventative medical team in chemical incidents. Occup Environ Med 1995;52:694-8.

5 Baxter PJ. Review of major chemical incidents and their medical management. In: Murray V, ed. Major chemical disasters-medical aspects of management. London: Royal Society of Medicine, 1990:7-20. (Royal Society of Medicine Services. International Congress and Symposium Series No155.)

bmj.com 2005;330:1471

Department of Public Health and Primary Care, University of Cambridge, Institute of Public Health, Cambridge CB2 2SR

Peter J Baxter consultant occupational physician

Pjb21@medschl.cam.ac.uk 